Secretariat of the Pacific Community

$6^{\text {th }}$ SPC Heads of Fisheries Meeting

(9-13 February 2009, Noumea, New Caledonia)

Background Paper 3

Original: English

\title{
Planning the use of fish for food security in the Pacific
}

\section{Johann D. Bell ${ }^{\mathrm{a}, *}$, Mecki Kronen ${ }^{\mathrm{a}}$, Aliti Vunisea ${ }^{\mathrm{a}}$, Warwick J. Nash ${ }^{\mathrm{b}}$, Gregory Keeble ${ }^{\mathrm{a}}$, Andreas Demmke ${ }^{a}$, Scott Pontifex ${ }^{a}$, Serge Andréfouët ${ }^{c}$}

\footnotetext{
a Secretariat of the Pacific Community, BP D5, 98848 Noumea, New Caledonia ${ }^{\mathrm{b}}$ WorldFish Center, C/- Secretariat of the Pacific Community, BP D5, 98848 Noumea, New Caledonia ${ }^{\mathrm{c}}$ Institut de Recherche pour le Développement, BP A5, 98848 Noumea, New Caledonia
} 
Marine Policy 33 (2009) 64-7G

Contents lists available at ScienceDirect

Marine Policy

Planning the use of fish for food security in the Pacific

Johann D. Bell ${ }^{\text {a,* }}$, Mecki Kronen ${ }^{\mathrm{a}}$, Aliti Vunised ${ }^{\mathrm{a}}$, Warwick J. Nash ${ }^{\mathrm{b}}$, Gregory Keeble ${ }^{\mathrm{a}}$,

Andreas Demmke ${ }^{\mathrm{a}}$, Scott Pontifex ${ }^{\mathrm{a}}$, Serge Andréfouët ${ }^{\mathrm{c}}$

asecretaniat of the Pacific Community, BP D5, 98848 Noumea, New Caledonia

${ }^{b}$ Worldfish Center, C/- Secretariat of the Pacific Community, BP D5, 98848 Noumea, New Caledonia

'Institut de Recherche pour le Développement, BP A5, 98848 Noumea, New Caledonia

"For information on how to access this article, please contact the SPC Library at library@spc.int" 